\title{
DELIMITACIÓN DEL BLOQUE DE CONSTITUCIONALIDAD EN EL CASO GUATEMALTECO
}

Delimitation of the constitutional bloc in the Guatemalan case

\section{Ana Isabel Calderón Cristal}

Licenciada en Ciencias Jurídicas y Sociales, Abogada y Notaria Maestranda en Derecho Constitucional, Universidad Rafael Landívar Letrada de Magistratura de la Corte de Constitucionalidad de Guatemala.

anaisacalderon3580@yahoo.com https://doi.org/10.37346/opusmagna.v16i01.9

Fecha de recepción: 07/10/2019

Fecha de aceptación: 20/02/2020 


\section{SUMARIO}

\section{Introducción}

1. Consideraciones preliminares

2. El bloque de constitucionalidad en el ámbito guatemalteco

3. Determinación de los instrumentos que conforman el bloque de constitucionalidad

Reflexiones finales

Bibliografía

\begin{tabular}{|c|}
\hline Resumen \\
\hline $\begin{array}{l}\text { El presente trabajo constituye un } \\
\text { intento de profundizar en el tema del } \\
\text { bloque de constitucionalidad en el } \\
\text { contexto guatemalteco, incursionando } \\
\text { en el campo de la delimitación de los } \\
\text { instrumentos internacionales que, a } \\
\text { través de la jurisprudencia de la Corte de } \\
\text { Constitucionalidad de Guatemala, han } \\
\text { sido considerados como integrantes de } \\
\text { esa figura, a partir del reconocimiento } \\
\text { expreso que, de esta última, efectuara } \\
\text { el alto tribunal. Pretende, pues, } \\
\text { avanzar en la identificación del elenco } \\
\text { normativo que ostenta actualmente } \\
\text { jerarquía constitucional y es susceptible } \\
\text { de constituirse como parámetro del } \\
\text { control de constitucionalidad de los } \\
\text { actos y leyes. Además, dejar plasmadas } \\
\text { algunas reflexiones sobre las importantes } \\
\text { implicaciones prácticas que la inclusión } \\
\text { de instrumentos internacionales en } \\
\text { el bloque posee con relación al deber } \\
\text { de cumplimiento de los compromisos } \\
\text { internacionales adquiridos por el } \\
\text { Estado de Guatemala y la protección de } \\
\text { derechos humanos de sus habitantes, } \\
\text { y que tocan a la totalidad de órganos } \\
\text { estatales, así como a los particulares. } \\
\text { Esto, a partir del nivel reforzado de } \\
\text { vinculatoriedad que se brinda a los } \\
\text { aludidos instrumentos al dotarlos de }\end{array}$ \\
\hline
\end{tabular}

Abstract
This work constitutes an attempt
to delve deeper into the issue of the
constitutional bloc in the Guatemalan
context by entering into the field of
the delimitation of the international
instruments. Some of these have been
considered by the Constitutional
Court of Guatemala as part of the
constitutional bloc through express
recognition in case law. It intends
to advance in the identification
of the norms that are currently of
constitutional hierarchy and are
capable of being constituted as a
parameter of the constitutionality
control of acts and laws. Additionally,
it reflects some considerations about
the important practical implications
that the inclusion of international
instruments in the bloc has. The
previous in relation to the duty of
compliance of the international
commitments acquired by the State
of Guatemala and the protection of
the human rights of its inhabitants
that affect all state organs, as well
as the individuals. This is based on
the reinforced level of binding force
that is given to the aforementioned
instruments by providing them
with the normative force that
the


la fuerza normativa que caracteriza a las disposiciones constitucionales. Se resalta, además, la necesidad de procurar líneas cada vez más claras cuando se aluda a los elementos integrantes de esta noción, a efecto de que la figura sea difundida de maneras más precisas en los distintos campos de aplicación jurídica.

Palabras clave: Derecho Procesal Constitucional, bloque de constitucionalidad, control de constitucionalidad, jerarquía constitucional, instrumentos internacionales en materia de derechos humanos, Corte de Constitucionalidad. characterizes the constitutional provisions. It also highlights the need to seek increasingly clear lines when referring to the constituent elements of this notion, in such a way that the figure can be disseminated in more precise ways in the various fields of legal application.

Keywords: Constitutional Procedural Law, constitutional bloc, constitutional control, constitutional hierarchy, international human rights instruments, Constitutional Court of Guatemala.

\section{ABREVIATURAS}

C 169 Convenio 169 de la Organización Internacional de Trabajo sobre pueblos indígenas y tribales en países independientes

CADH Convención Americana sobre Derechos Humanos

CC Corte de Constitucionalidad de Guatemala

Corte IDH Corte Interamericana de Derechos Humanos 


\section{INTRODUCCIÓN}

El presente trabajo no tiene otra pretensión más que la de avanzar en la tarea de perfilar el bloque de constitucionalidad en el contexto guatemalteco. No busca ahondar en los orígenes de la figura o realizar un ejercicio de derecho comparado que dé cuenta de su tratamiento en otras latitudes. Baste realizar algunas breves referencias de los extremos mencionados, que sirvan como introducción para el abordaje del asunto principal que busca ser desarrollado. Pese a que la noción del bloque ya ha sido abordada en algunos trabajos locales precedentes, el presente se constituye como un intento de profundización, mediante la incursión en el campo de la delimitación de los instrumentos internacionales que por vía pretoriana han sido considerados como integrantes del bloque a partir del reconocimiento expreso que, de esta figura, realizó el tribunal constitucional. No es ajena la complejidad de lograr un alto grado de precisión en una labor de sistematización de la jurisprudencia del tribunal constitucional guatemalteco como la que se procura, principalmente ante el gran cúmulo de asuntos que son sometidos a su conocimiento y en los que son invocados materiales jurídicos internacionales, así como la no siempre clara delimitación realizada en los fallos constitucionales. A pesar de lo anterior, se considera necesario el emprendimiento de esa tarea, ante las importantes implicaciones prácticas que posee el empleo de figuras como el bloque de constitucionalidad y, estrechamente relacionado, el control de convencionalidad.

El recorrido inicia, pues, con una serie de consideraciones preliminares que hacen mención del origen de la figura y su recepción en el continente latinoamericano. Posteriormente, serán incluidos aspectos generales que van caracterizando al bloque de constitucionalidad en el ámbito local. En un tercer segmento, será abordado el criterio de la determinación de los instrumentos que conforman el bloque en el contexto nacional, así como la serie de materiales jurídicos que pueden ser considerados incluidos en este. Finalmente, las consideraciones efectuadas permitirán concluir sobre la importancia de establecer, con claridad, cuáles instrumentos internacionales ostentan actualmente jerarquía constitucional y resultan ser susceptibles de constituirse como parámetro del control de constitucionalidad de los actos y leyes. Además, reflexionar sobre la repercusión que ello posee en la tarea 
que a cada uno de los entes públicos corresponde en el cumplimiento de los compromisos internacionales adquiridos por el Estado de Guatemala.

Para lograr el objetivo trazado, el presente trabajo se vale del análisis realizado sobre diversos pronunciamientos emitidos por el alto tribunal constitucional en los que quedó plasmada la invocación de la noción del bloque de constitucionalidad, proveniente de la labor argumentativa realizada por las partes o por la mencionada Corte, a partir de los cuales se seleccionaron aquellos que, a juicio de la autora, permiten identificar la utilización del contenido de ciertos materiales jurídicos, distintos al texto formal de la norma suprema, en la labor de control de constitucionalidad ejercida por el Tribunal. 


\section{Consideraciones preliminares}

Al tratar el tema de los orígenes de la noción de bloque de constitucionalidad, surge imperativamente la necesidad de hacer referencia a la labor efectuada por el Consejo Constitucional francés, que cuando estudia la constitucionalidad de una disposición legal frente a la Constitución francesa de 1958 [decisión 71-44 DC, de 1971] hace remisión a la Declaración de Derechos del Hombre y del Ciudadano de 1789 y al preámbulo de la Constitución francesa de 1946. El referido Consejo acudió a tales documentos debido a que en la norma constitucional vigente no existe un catálogo expreso de derechos, como sí existía en otros instrumentos. Ese vacío es superado atendiendo el tenor literal del preámbulo del texto fundamental, ${ }^{1}$ que el Consejo entiende dotado de fuerza vinculante. La doctrina francesa acuña el término bloque de constitucionalidad para explicar la técnica empleada por el Consejo Constitucional, inspirada en lo que en derecho administrativo era denominado bloque de legalidad, que evocaba a todas las reglas de origen variado que se imponen a la administración en virtud del principio de legalidad. El vocablo es un término acuñado doctrinalmente, pues hasta ese entonces, el Tribunal francés, al designar el conjunto de disposiciones situadas a nivel constitucional, cuyo respeto se impone a la ley, prefería expresiones como la de principios y reglas de valor constitucional (Favoreau, 1990).

A partir de entonces, la utilización de la figura del bloque de constitucionalidad se ha expandido en numerosos países, tanto en Europa como en América; sin embargo, perfila un contenido diferente en cada continente, pues en el ámbito europeo, su empleo se encuentra vinculado a la remisión de normas nacionales que sirven como parámetro de constitucionalidad; en contraste, la región americana ha utilizado el bloque en estrecha relación con las cláusulas constitucionales de apertura al derecho internacional de los derechos humanos.

$1 \quad$ El preámbulo establece: "El pueblo francés proclama solemnemente su adhesión a los derechos humanos y a los principios de la soberanía nacional tal y como fueron definidos por la Declaración de 1789, confirmada y completada por el Preámbulo de la Constitución de 1946..." (Constitución, 1958). Actualmente, producto de una reforma realizada en 2005, el preámbulo también hace referencia a los derechos y deberes definidos en la Carta de Medio Ambiente de 2003. 
Así lo explica Góngora Mera (2014) cuando nota, en un estudio de derecho comparado, que en Estados como Francia, España e Italia, el bloque de constitucionalidad hace referencia al conjunto de normas que conforman el parámetro de constitucionalidad, incluyendo a la constitución stricto sensu y una serie de normas de origen nacional, que no pertenecen al texto constitucional y que pueden tener formalmente el mismo rango de las normas cuya constitucionalidad es discutida. Mientras que en el caso francés, mediante el bloque de constitucionalidad se integran normas de derechos humanos reconocidos en instrumentos nacionales previos a la Constitución vigente, en España e Italia la figura es empleada primordialmente en la distribución de competencias entre el Estado y las autoridades regionales. ${ }^{2}$

Luego de un repaso del bloque de constitucionalidad en el ámbito latinoamericano, el citado autor asevera que la adopción de esta figura supone que varios tratados internacionales de derechos humanos han adquirido rango constitucional en distintos países, lo que ha generado una convergencia normativa en el derecho constitucional de varios Estados. Concluye que, pese a la heterogeneidad respecto de las normas que efectivamente se integran al bloque, la expansión intra-regional de su doctrina ofrece un potencial muy significativo para la convergencia de estándares normativos en materia de derechos humanos y, consecuentemente, para la construcción colectiva de un ius constitutionale commune en América Latina.

Las breves anotaciones efectuadas dan cuenta de la dificultad de efectuar delimitaciones conceptuales cuando al bloque de constitucionalidad se refiere. De cualquier forma, se estima conveniente señalar que este concepto refiere, en términos generales, al conjunto de disposiciones contenidas textualmente en la norma fundamental, y aquellas que aun no siendo dispuestas de esa forma, por remisión del mismo texto supremo, o bien, producto de construcciones

2 Al parecer de Góngora Mera, la adaptación en la región americana de la figura del bloque de constitucionalidad a las condiciones propias de cada país obedeció a distintos factores de la coyuntura político institucional, dentro de los que se enlistan los procesos de democratización y las reformas constitucionales desde finales de los ochenta, que incluyeron referencias explícitas a diversos instrumentos internacionales en materia de derechos humanos, universales y regionales, así como la creación, en varios casos, de cortes constitucionales independientes. 
jurisprudenciales a cargo de los órganos que ejercen jurisdicción constitucional, adquieren jerarquía constitucional y pueden ser utilizadas como parámetro para efectuar el control de constitucionalidad. En su versión latinoamericana, el bloque de constitucionalidad ha sido empleado primordialmente como técnica de apertura al derecho internacional de los derechos humanos.

\section{El bloque de constitucionalidad en el ámbito guatemalteco}

En Guatemala, la constitución no consagra explícitamente la jerarquía constitucional de instrumentos internacionales en materia de derechos humanos, como sí sucede en otros países, por ejemplo, en Argentina (Congreso Nacional Constituyente, 1994), donde la norma fundamental, enumera instrumentos claramente definidos a los que asigna ese rango. Sí incluye la constitución guatemalteca, empero, el precepto siguiente: "Artículo 46. Preeminencia del Derecho Internacional. Se establece el principio general de que en materia de derechos humanos, los tratados y convenciones aceptados y ratificados por Guatemala, tienen preeminencia sobre el derecho interno". Asimismo, el artículo 44 establece: "Derechos inherentes a la persona humana. Los derechos y garantías que otorga la Constitución no excluyen otros que, aunque no figuren expresamente en ella, son inherentes a la persona humana..." (Asamblea Nacional Constituyente, 1985).

Aunque pudiera deducirse, prima facie, que el derecho interno incluye también a la norma fundamental guatemalteca, sobre la cual, el derecho internacional también tendría preeminencia, conforme el artículo 46 ibídem, tal apreciación ha sido discutida. En una postura inicial, expresada dentro del expediente 280-90, la CC consideró que la jerarquización a la que hace alusión el artículo 46 debía entenderse respecto a la legislación ordinaria o derivada, pero no podía reconocerse sobre la Constitución, porque si derechos no incluidos expresamente en ella (pero cuya protección es reconocida por vía del artículo 44 constitucional) entraran en contradicción con sus preceptos, su efecto sería modificador o derogatorio, lo cual provocaría conflicto con las cláusulas constitucionales que garantizan su rigidez y superioridad, y con la disposición que únicamente el poder constituyente o el refrendo popular, según sea el caso, tienen facultad reformadora de la Constitución (Corte de Constitucionalidad, 1990). 
Posteriormente, el citado tribunal constitucional determinaría, dentro de los expedientes 334-95 y 131-95, que de existir conflicto entre normas de derecho interno y tratados internacionales sobre derechos humanos, prevalecerían estos últimos, sin embargo, también afirmaría que estos no son parámetros de control constitucional (Corte de Constitucionalidad, 1996, 1997).

Un poco más adelante, la CC variaría su interpretación al reconocer, implícitamente, que los tratados internacionales en materia de derechos humanos constituyen parámetro de constitucionalidad de los actos de poder público y leyes. Ejemplificativo de lo anterior, es el pronunciamiento proferido dentro del expediente 1042-97 (Corte de Constitucionalidad, 1998). A partir de entonces, paulatinamente, la CC iría incorporando, en su tesis argumentativa, la figura del bloque de constitucionalidad.

Imprescindible, al momento de tratar el tema del bloque de constitucionalidad, resulta el fallo emitido dentro del expediente 1822-2011, en que el tribunal constitucional estima importante hacer un esfuerzo por perfilar con mayor nivel de precisión la figura objeto de estudio. En esa oportunidad consideró:

... para dar respuesta a la problemática acerca de la recepción en el orden interno de los tratados en materia de derechos humanos, otros ordenamientos han acudido a la figura del bloque de constitucionalidad, el que ha sido parte de anteriores pronunciamientos de la Corte de Constitucionalidad, (verbigracia los expedientes 90-90, 159-97, 30042007, 3878-2007, auto de 4 de octubre de 2009, expediente 3690-2009, 1940-2010 y 3086-2010, entre otros), aunque en ninguno de éstos se ha definido su contenido y alcances.

Luego de efectuar algunas consideraciones sobre la evolución de la que ha sido objeto la figura del bloque de constitucionalidad en el derecho comparado, la CC dictaminó:

...por vía de los artículos 44 y 46 citados, se incorpora la figura del bloque de constitucionalidad como un conjunto de normas internacionales referidas a derechos inherentes a la persona, incluyendo todas aquéllas 
libertades y facultades que aunque no figuren en su texto formal, respondan directamente al concepto de dignidad de la persona, pues el derecho por ser dinámico, tienen reglas y principios que están evolucionando y cuya integración con esta figura permite su interpretación como derechos propios del ser humano. El alcance del bloque de constitucionalidad es de carácter eminentemente procesal, es decir, que determina que los instrumentos internacionales en materia de derechos humanos que componen aquél son también parámetro para ejercer el control constitucional del derecho interno. Así, a juicio de esta Corte, el artículo 46 constitucional denota la inclusión de los tratados en el bloque de constitucionalidad, cuyo respeto se impone al resto del ordenamiento jurídico, exigiendo la adaptación de las normas de inferior categoría a los mandatos contenidos en aquellos instrumentos. El contenido del bloque de constitucionalidad está perfilado por la Constitución, y esta Corte, como máximo intérprete de la norma suprema, cuyas decisiones son vinculantes a los poderes públicos, es la competente para determinar, en cada caso, qué instrumentos se encuentran contenidos en aquél (Corte de Constitucionalidad, 2012).

El tribunal guatemalteco ha afirmado expresamente, verbigracia, en el expediente 5237-2013, la utilización del bloque de constitucionalidad en el control constitucional deleyes, señalando que: "La acción deinconstitucionalidad procede contra las normas jurídicas vigentes que contengan vicio total o parcial de inconstitucionalidad, en aras de que el ordenamiento jurídico esté integrado solamente por disposiciones que se enmarquen en los postulados del bloque de constitucionalidad." (Corte de Constitucionalidad, 2015).

Sin embargo, resulta de importante mención el hecho que, desde los primeros fallos subsiguientes al emitido dentro del expediente 1822-2011 precitado (por ejemplo, en los expedientes acumulados 5909-2013, 5985-2013, 48-2014 y 439-2014, 2404-2014, acumulados 5341-2015 y 5350-2015, y 19072017) puede advertirse que el empleo del bloque de constitucionalidad perfilado por la CC no se limita al control de normas jurídicas, sino que, además, de los actos del poder público. En los siguientes términos se ha manifestado, en cuanto a la posibilidad de cuestionar violaciones o amenazas de violación de derechos humanos por medio de la garantía del amparo: “...el amparo se circunscribe a 
intervenir ante la amenaza o lesión a los derechos que la Constitución, el bloque de constitucionalidad o el resto del orden jurídico reconocen y garantizan..." (Corte de Constitucionalidad, 2015) (Corte de Constitucionalidad, 2016) (Corte de Constitucionalidad, 2016) (Corte de Constitucionalidad, 2018).

Esta última acotación resulta de importante mención, pues como señala Casal (2010) al referirse a las funciones de la jurisdicción constitucional, se observa un desplazamiento en el tratamiento dogmático de esa jurisdicción, que en una primera etapa giró en torno al control constitucional de las leyes, pero posteriormente, ha desembocado en una intensificación de las tareas de control sobre los jueces ordinarios, mediante mecanismos como el amparo, lo que ocurre en Alemania y España. Lo anterior conlleva, para el citado autor, la necesidad de realizar un reexamen de las funciones de la jurisdicción constitucional, que suelen perfilarse centrándose en la revisión de leyes, pese a que esta no es, en muchos ordenamientos, el principal campo de actuación de esa jurisdicción.

El citado tribunal nacional también ha señalado que la interpretación de las normas jurídicas debe efectuarse observando los principios contenidos en la Constitución yel resto de normas que conforman el bloque de constitucionalidad, con lo cual vincula no solamente al órgano legislativo -y demás autoridades con potestad regulatoria- en la producción de las disposiciones normativas, sino a todos los órganos estatales e, incluso, a los particulares. De esta forma lo apuntó, dentro de los expedientes 3137-2015 y 3370-2015:

Así, esta Corte ha sostenido que la interpretación jurídica en un Estado Constitucional de derecho debe realizarse de forma sistemática, teniendo presente la necesaria sujeción del orden jurídico interno a los preceptos de la Constitución, lo que implica que tanto los órganos del Estado, como los particulares o gobernados, están obligados a interpretar las normas jurídicas en coherencia con los principios y postulados que emanan de la Ley Fundamental y del resto de normas que conforman el bloque de constitucionalidad (Corte de Constitucionalidad, 2015) (Corte de Constitucionalidad, 2016). 
De la misma forma, la Corte ha afirmado que la interpretación del texto de la Constitución debe realizarse de forma integral, observando los principios y normas del resto de instrumentos que integran el bloque de constitucionalidad, aseveración que atañe a todos los órganos que se constituyen como tribunales constitucionales, incluso a la CC misma, como intérprete última del texto fundamental. En ese sentido, dentro del expediente 4076-2016, expresó lo siguiente: “...la interpretación de la Constitución Política de la República de Guatemala debe ser de forma integral, analizando y ponderando todas las normas y principios del bloque de constitucionalidad" (Corte de Constitucionalidad, 2016).

\section{Determinación de los instrumentos que conforman el bloque de constitucionalidad}

Previo al fallo proferido dentro del expediente 1822-2011 arriba aludido (17 de julio de 2012), el tribunal constitucional, dentro del expediente 38782007, empleó como criterio determinante para considerar a un documento multilateral incluido dentro de la figura, su ratificación por parte del Estado de Guatemala. De la siguiente forma se expresó:

Como puede advertirse, el consentimiento y/o la ratificación de lo dispuesto en los documentos multilaterales antes enumerados supone para el Estado de Guatemala, en síntesis, el compromiso internacional de asumir una posición definida acerca del derecho de consulta de los pueblos indígenas, expresada en varios componentes: (i) su reconocimiento normativo propiamente dicho y, por ende, su inserción al bloque de constitucionalidad como derecho fundamental, por virtud de lo establecido en los artículos 44 y 46 de la Carta Magna... (Corte de Constitucionalidad, 2009)

Esa postura variaría en el pronunciamiento emitido en el expediente 1822-2011, en el que la CC indicó que sería ese tribunal el que iría estableciendo los instrumentos que se encontrarían contenidos en el bloque, de lo que puede entenderse que la sola manifestación de consentimiento del Estado no resultaría suficiente para considerar a un instrumento como integrante de la figura. Este criterio de selección de los instrumentos por parte del máximo tribunal 
constitucional como mecanismo para la conformación de la noción de bloque fue reiterado expresamente en diversas oportunidades subsiguientes.

Debe advertirse, no obstante lo anterior, sobre la existencia de sentencias, también posteriores, no del todo claras con relación a la adopción de ese último criterio. En apoyo de tales pronunciamientos, se puede asumir una $\mathrm{u}$ otra postura, dado que la CC no es expresa en señalar la circunstancia a partir de la cual considera que los instrumentos internacionales que emplea tienen aptitud para servir como parámetro del control constitucional, en contraste con otras oportunidades, en la que sí indica que la observancia de cierto instrumento obedece a su inserción al bloque, por parte del mismo Tribunal, en fallos precedentes. Además, se registran ocasiones en las que la Corte, sin hacer alusión explícita a la figura del bloque, sí realiza una labor de parificación entre normas o actos y fuentes internacionales, razón por la que estas decisiones se incluyen dentro del grupo de sentencias en el que no es posible la identificación del criterio empleado.

A continuación, una figura que contiene los pronunciamientos ubicados, dispuestos en orden cronológico y en atención a los criterios de inclusión utilizados por la Corte. 


\section{Figura 1}

Línea jurisprudencial del mecanismo adoptado para determinar la conformación del bloque de constitucionalidad

\begin{tabular}{|c|c|c|c|c|}
\hline $\begin{array}{l}\text { Manifestación } \\
\text { de } \\
\text { consentimiento } \\
\text { del instrumento } \\
\text { internacional } \\
\text { por parte del } \\
\text { Estado de } \\
\text { Guatemala } \\
\text { Manifestación } \\
\text { de } \\
\text { consentimiento } \\
\text { del instrumento } \\
\text { internacional } \\
\text { por parte del } \\
\text { Estado de } \\
\text { Guatemala }\end{array}$ & $\begin{array}{l}\text { Sentencia de } 21 \\
\text { de diciembre de } \\
\text { 2009, expediente } \\
3878-2007\end{array}$ & 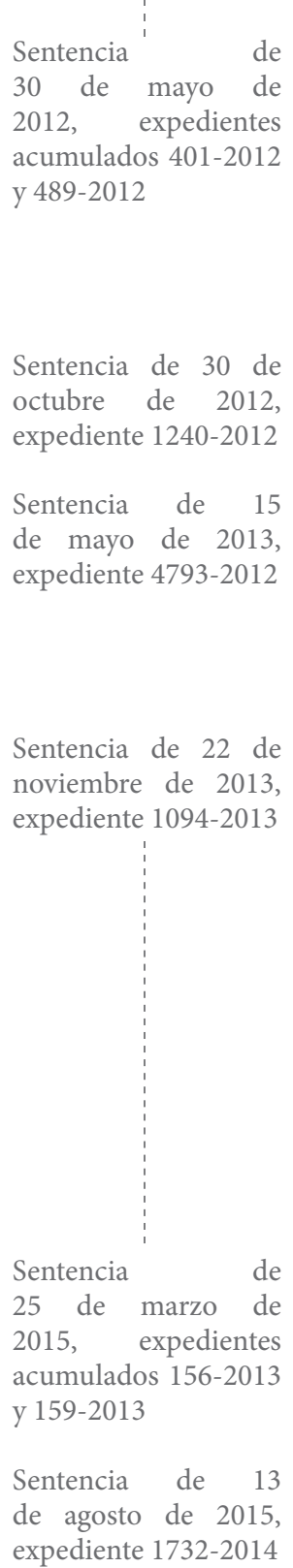 & $\begin{array}{l}\text { Sentencia de } 7 \text { de } \\
\text { agosto de 2013, } \\
\text { expediente 1497- } \\
2013 \\
\\
\text { Sentencia de } \\
19 \text { de marzo de } \\
2014 \text {, expediente } \\
\text { 1552-2013 } \\
\text { Sentencia de } 26 \\
\text { de febrero de } \\
\text { 2015, expedientes } \\
\text { a c u m u la d o s } \\
3308-2014 \\
3347-2014\end{array}$ & $\begin{array}{c}\text { Inclusión del } \\
\text { instrumento, } \\
\text { por parte de } \\
\text { la CC }\end{array}$ \\
\hline
\end{tabular}




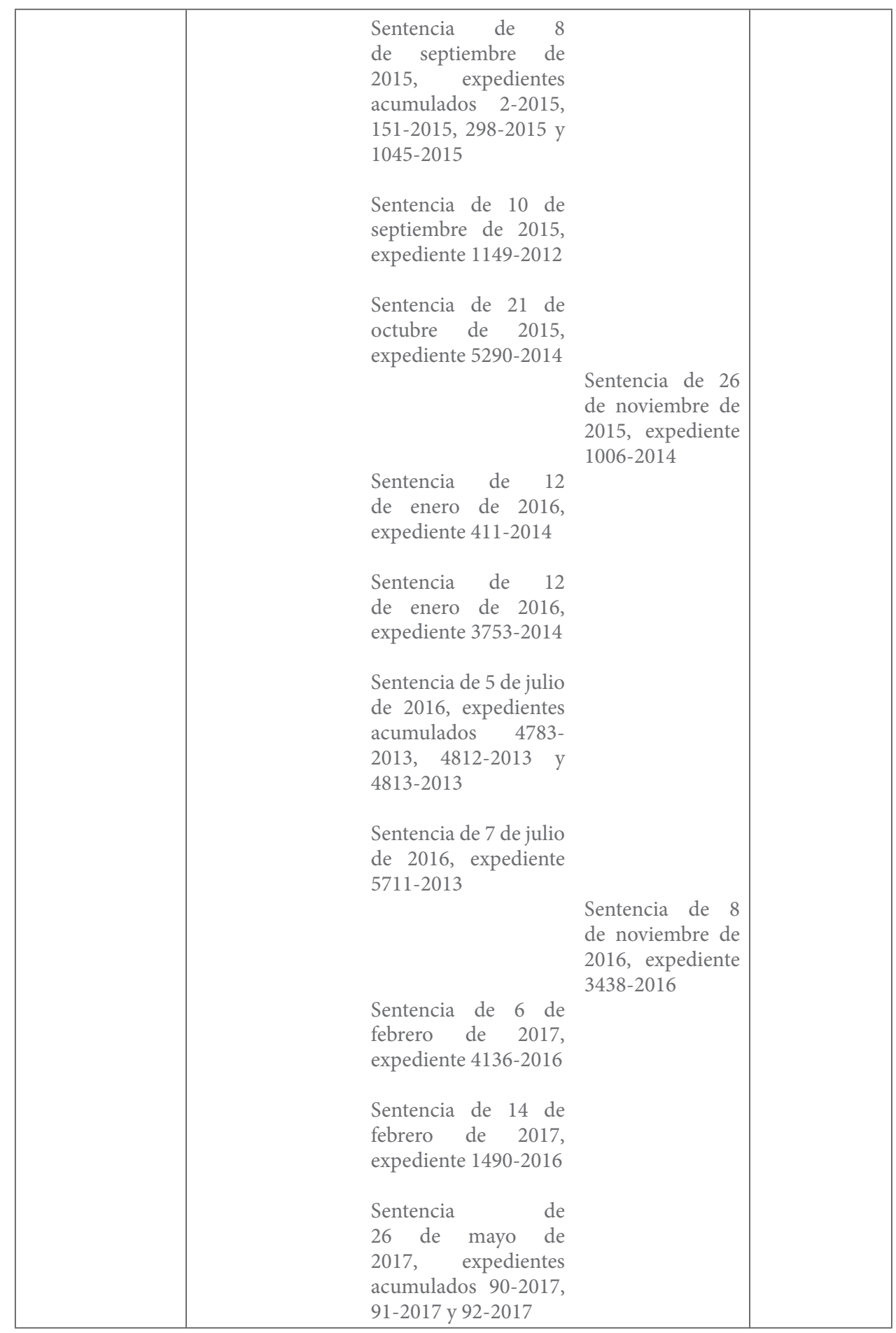




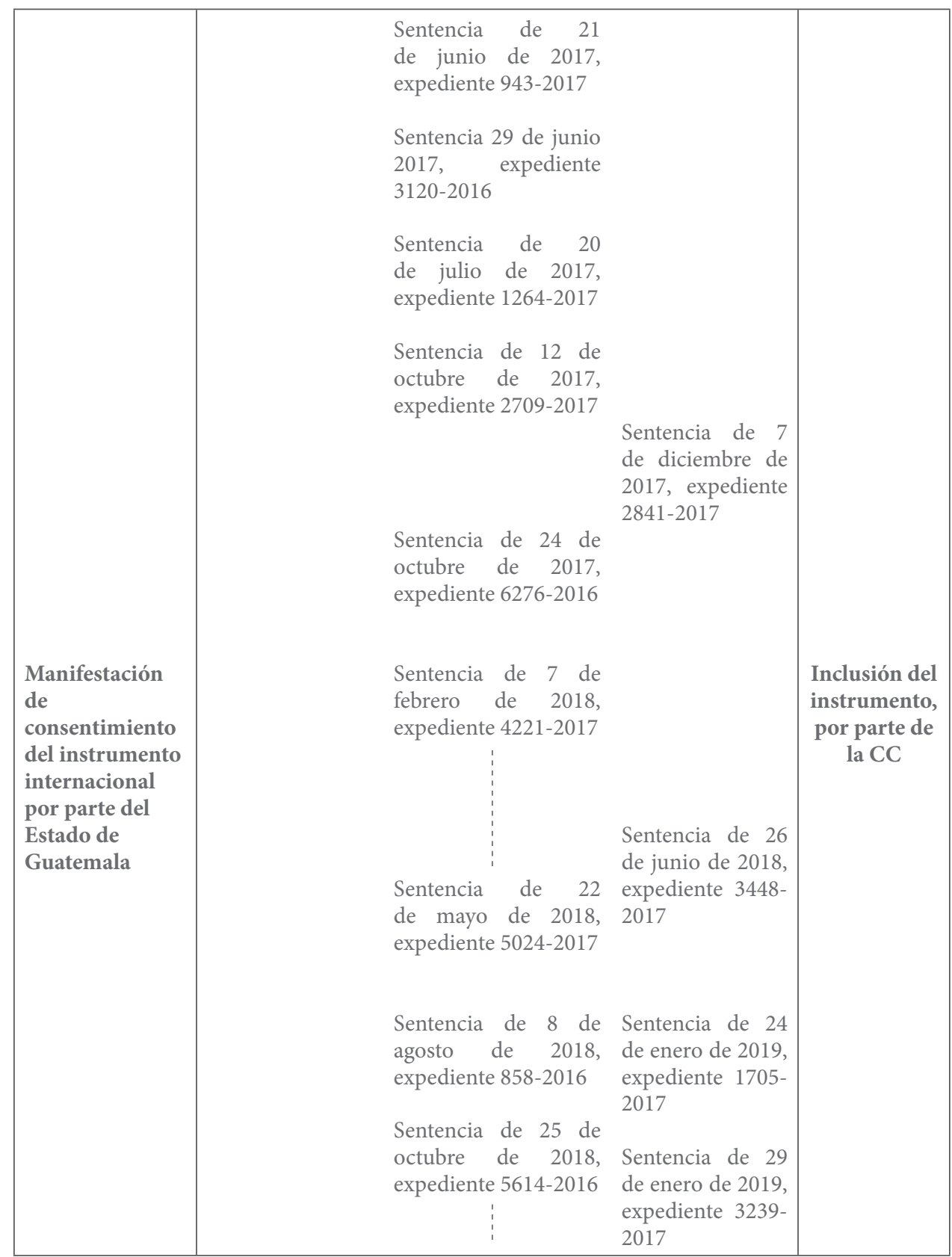

Como puede observarse, la Corte no ha sido conteste en la expresión de los motivos que la llevan a apreciar que un instrumento internacional puede ser considerado parte del bloque de constitucionalidad. Pese a ello, 
existen razones para sostener que la escogencia de los materiales jurídicos que pueden considerarse insertos al bloque corresponde al máximo tribunal constitucional guatemalteco. Estas serían: i) en la sentencia proferida dentro del expediente 1822-2011, el Tribunal se atribuyó de forma explícita esa potestad; ii) existen diversas resoluciones que reiteran ese criterio, y iii) no fue ubicado pronunciamiento posterior al emitido dentro del expediente 1822-2011 del que pueda extraerse, sin lugar a dudas, el empleo del criterio anterior, contenido en la sentencia dictada dentro del expediente 3878-2007, por virtud del cual se sostenía que los instrumentos internacionales automáticamente integraban el bloque al ser ratificados por el Estado.

Expresado lo anterior, resulta pertinente examinar, desde la mirada del criterio que sostiene que la $\mathrm{CC}$ es la competente para determinar los instrumentos que se encuentran contenidos en él, cuáles materiales jurídicos pueden considerarse, en efecto, incluidos en el bloque, sea por su incorporación expresa o tácita en los casos analizados.

La Corte ha afirmado en reiteradas ocasiones que es dable esgrimir lo preceptuado por la CADH como parámetro para establecer la legitimidad constitucional de una disposición infraconstitucional, así como en el enjuiciamiento de actos del poder público. También dispuso la CC, cuando se intentó cuestionar la constitucionalidad de precepto contenido en la $\mathrm{CADH}$, que esa disposición, al formar parte del bloque de constitucionalidad, no podía ser objeto de un planteamiento de esa naturaleza.

Otros instrumentos internacionales que pueden ser considerados como parte del elenco del bloque de constitucionalidad, conforme el criterio del que se ha hecho mención, lo son: la Declaración Universal de Derechos Humanos, el Protocolo Adicional a la Convención Americana sobre Derechos Humanos en materia de Derechos Económicos, Sociales y Culturales, el Pacto Internacional de Derechos Civiles y Políticos, el Pacto Internacional de Derechos Económicos, Sociales y Culturales, la Convención contra la Tortura y otros Tratos o Penas Crueles, Inhumanos o Degradantes y su Protocolo Facultativo, la Convención Interamericana para Prevenir y Sancionar la Tortura, la Convención sobre los Derechos del Niño y, con un menor grado de 
determinación, los estándares internacionales protectores de los derechos de niños, niñas y adolescentes, la Convención sobre la Eliminación de todas las Formas de Discriminación contra la Mujer, la Convención Interamericana para Prevenir, Sancionar y Erradicar la Violencia contra la Mujer "Convención de Belém do Pará, la Convención sobre la Nacionalidad de la Mujer Casada y, de forma general, los tratados internacionales en materia de derechos de la mujer, las Reglas Mínimas de las Naciones Unidas sobre las medidas no privativas de la libertad (Reglas de Tokio), la Convención sobre los Derechos de las Personas con Discapacidad, el Convenio 98 de la Organización Internacional de Trabajo sobre el derecho de sindicación y de negociación colectiva, el Convenio 154 de la Organización Internacional de Trabajo sobre la negociación colectiva, la Convención Internacional sobre la Protección de los Derechos de Todos los Trabajadores Migratorios y sus Familiares y la Convención sobre el Estatuto de los Apátridas.

Con relación al C 169, la jurisprudencia de la CC no ha sido contundente sobre si esa normativa, en su totalidad, forma parte del bloque de constitucionalidad. Aunque inicialmente el tribunal no parecía tener una postura clara respecto de si las disposiciones de ese cuerpo normativo podían condicionar actos públicos, particularmente, la formación de leyes, ${ }^{3}$ son halladas oportunidades en la que fue explícita en indicar que el citado

3 Cuando, dentro del expediente 1008-2012, se impugnó de inconstitucional la Ley de Minería, pues en su contenido no se contempló el derecho de consulta; además, se afirmó que como medida legislativa debió ser sometida a consulta antes de ser formulada, según los lineamientos contenidos en el C 169. En sus consideraciones, la CC refirió: “... es preciso mencionar que el proceso de formación y sanción de la ley en Guatemala, se encuentra establecido a nivel constitucional, en los artículos 174 al 181 de la norma suprema, procedimiento utilizado para la emisión de la Ley que se cuestiona, sin que pueda apreciarse en el reproche que se formula se refiera al incumplimiento de las etapas previstas en la normativa antes indicada. Si bien, se cuestiona que a juicio de los accionantes, debió darse cumplimiento a la previsión contenida en el Convenio 169 de la Organización Internacional del Trabajo, a juicio de este Tribunal en el proceso de formación y sanción de la ley deviene aplicable la normativa antes indicada, por lo que no resulta acogible el citado argumento". Sin embargo, más adelante, el Tribunal plasmaría apreciaciones sobre la forma en que, en cada caso concreto, según interpretó, podía darse cumplimiento a la obligación de consulta contenida en el referido instrumento. Nótese que la sentencia a la que se ha hecho referencia es posterior a la emitida dentro del expediente 1822-2011 (de 17 de julio de 2012), en la que se abordó de forma expresa el reconocimiento del bloque de constitucionalidad (Corte de Constitucionalidad, 2013). 
convenio constituye parte integrante del bloque. ${ }^{4}$ Existe también abundante jurisprudencia en la que se reitera que el derecho de consulta, previsto en esa normativa, es parte del bloque, y casos en los que ha empleado disposiciones del C 169, distintas a aquellas relacionadas al derecho de consulta, como parámetro para la verificación de la constitucionalidad, en algunas ocasiones, sin referir con claridad que el cuerpo normativo integra el bloque, pero sí haciéndolo, respecto de los estándares internacionales en materia de derechos humanos.

Sobre la Declaración de Naciones Unidas sobre los Derechos de los Pueblos Indígenas, es importante mencionar que la CC ha señalado, en alguna ocasión, que esta forma parte del bloque de constitucionalidad, invocándola para efectuar la labor de control, ${ }^{5}$ pero, en otros casos, principalmente la ha reconocido como pauta interpretativa que da sentido y alcance a los derechos contenidos en los otros instrumentos internacionales, en consonancia con la manifestación que el Estado de Guatemala efectuó en el voto favorable que, en su oportunidad, emitiera para su aprobación en la Asamblea General de las Naciones Unidas. ${ }^{6}$

Por otra parte, en algunos pronunciamientos, el tribunal constitucional precisó que al estar Guatemala sometida a la jurisdicción de la Corte IDH, resultaba de obligatoria observancia las sentencias emitidas por ese Tribunal, aunque en estas no figure el Estado de Guatemala como parte, ya que contienen la interpretación del contenido de las normas de la Convención. ${ }^{7}$ Sin embargo, en fallos más recientes, la Corte daría un paso adelante al reconocer

4 Por ejemplo, dentro de los expedientes acumulados 90-2017, 91-2017 y 92-2017, cuando señaló: "No está demás subrayar que el derecho de los pueblos indígenas a estar plenamente informados, se deriva del derecho de estos pueblos a determinar y elaborar las prioridades y estrategias de desarrollo o la utilización de sus tierras o territorios y otros recursos. Artículo 7.1, del Convenio 169 de la OIT, instrumento que como ya se ha mencionado con antelación forma parte de la Constitución Política de la República como consecuencia de su incorporación a la misma como Bloque de Constitucionalidad." (Corte de Constitucionalidad, 2017). Otro ejemplo es hallado dentro de los expedientes acumulados 401-2012 y 489-2012 (Corte de Constitucionalidad, 2012).

$5 \quad$ En tal sentido, el fallo emitido dentro de los expedientes acumulados 4783-2013, 48122013 y 4813-2013 (Corte de Constitucionalidad, 2016).

$6 \quad$ En esa línea, las sentencias dentro de los expedientes 943-2017 y 1467-2014 (Corte de Constitucionalidad, 2017) (Corte de Constitucionalidad, 2016).

7 Ver fallos emitidos dentro de los expedientes 3340-2013 y 1006-2014 (Corte de Constitucionalidad, 2014) (Corte de Constitucionalidad, 2015). 
expresamente que la jurisprudencia de la Corte IDH también forma parte del bloque de constitucionalidad.

Sobre la posibilidad de que normas de carácter local puedan integrar el bloque de constitucionalidad en el ámbito guatemalteco, conviene señalar que la CC ha traído a colación, en sus pronunciamientos, la opinión doctrinal que refiere que las leyes de carácter constitucional -Ley de Emisión del Pensamiento, Ley Electoral y de Partidos Políticos, Ley de Orden Público, y Ley de Amparo, Exhibición Personal y de Constitucionalidad- forman parte del bloque de constitucionalidad; ${ }^{8}$ sin embargo, esta referencia es utilizada por el Tribunal, no con el objeto de establecer que esas normativas ostentan jerarquía constitucional y puedan fungir como parámetro de control de constitucionalidad, sino únicamente a fin de realizar consideraciones sobre la posición preferente que ocupan respecto de la norma ordinaria y su especial proceso de reforma, así como de la competencia de la Corte para realizar un control preventivo y vinculante respecto a proyectos de reformas que sobre ellas se intenten. Por lo tanto, se considera que el enfoque que, del concepto de bloque de constitucionalidad, refiere el tribunal en los fallos citados, es distinto al analizado en el presente trabajo.

Otro punto conveniente de mencionar, lo es la consideración de si los Acuerdos de Paz signados entre el Gobierno de Guatemala y la Unidad Revolucionaria Nacional Guatemalteca forman parte del bloque. ${ }^{9}$ Hasta donde alcanza la información, este tema no ha sido objeto de tratamiento por parte del tribunal guatemalteco.

$8 \quad$ Resoluciones emitidas dentro de los expedientes 4708-2012 y 919-2016 (Corte de Constitucionalidad, 2013) (Corte de Constitucionalidad, 2017). Mismos enfoques son encontrados en los expedientes 90-90 y 159-97 (Corte de Constitucionalidad, 1990) (Corte de Constitucionalidad, 1998).

$9 \quad$ En el caso colombiano, la intención de que el Acuerdo Final para la Terminación del Conflicto y la Construcción de una Paz Estable y Duradera, suscrito entre el Gobierno de Colombia y la guerrilla, se calificara expresamente en el ordenamiento constitucional como acuerdo especial bajo derecho internacional humanitario y como parte integrante en estricto sentido del bloque de constitucionalidad, no prosperó; la Corte Constitucional colombiana tampoco conoció el fondo de la solicitud que le fue dirigida para ese efecto (Amaya-Villarreal y Guzmán Duarte, 2017). 
Por otro lado, resulta interesante la determinación si, en alguna ocasión, la CC ha excluido la posibilidad, expresamente, de que un instrumento internacional forme parte del bloque de constitucionalidad. Esto se registra, por lo menos, en una ocasión, en la que el tribunal constitucional, dentro del expediente 143-2013, señaló que la Convención de Viena sobre Derecho de los Tratados no forma parte del mencionado bloque, considerando que:

...ello no implica que [la Convención de Viena sobre Derecho de los Tratados], se convierta en un Instrumento Internacional de Derechos Humanos y por ende le amerite ser parte del bloque de constitucionalidad antes aludido y que pueda ser parámetro de constitucionalidad del marco jurídico nacional. La intención del legislador constituyente, plasmada en los artículos 44 y 46 constitucionales, fue respecto de los tratados cuyo contenido sea precisamente en materia de Derechos Humanos, lo que no concurre en la Convención de Viena que el accionante trata de utilizar como marco de referencia o parámetro de constitucionalidad... (Corte de Constitucionalidad, 2013).

Habiendo quedado señalado lo anterior, en la siguiente tabla se presenta el listado de instrumentos internacionales y la jurisprudencia que, conforme el análisis realizado en el presente trabajo, permite calificarlos como integrantes del bloque de constitucionalidad.

\section{Tabla 1}

Instrumentos incluidos dentro del bloque de constitucionalidad

\begin{tabular}{|l|l|}
\hline $\begin{array}{l}\text { Declaración Universal de } \\
\text { Derechos Humanos }\end{array}$ & $\begin{array}{l}\text { Sentencia de } 8 \text { de septiembre de 2015, } \\
\text { expedientes acumulados 2-2015, 151-2015, } \\
\text { 298-2015 y 1045-2015; sentencia de 5 de julio } \\
\text { de 2016, expedientes acumulados 4783-2013, } \\
\text { 4812-2013 y 4813-2013. }\end{array}$ \\
\hline
\end{tabular}




\begin{tabular}{|c|c|}
\hline Instrumento internacional & $\begin{array}{c}\text { Sentencias emitidas por la Corte de } \\
\text { Constitucionalidad }\end{array}$ \\
\hline $\mathrm{CADH}$ & $\begin{array}{l}\text { Sentencia de } 15 \text { de mayo de 2013, expediente } \\
\text { 4793-2012; sentencia de 22 de noviembre de } \\
\text { 2013, expediente 1094-2013; sentencia de } 26 \\
\text { de febrero de 2015, expedientes acumulados } \\
3308-2014 \text { y 3347-2014; sentencia de } 13 \\
\text { de agosto de 2015, expediente 1732-2014; } \\
\text { sentencia de 26 de noviembre de 2015, } \\
\text { expediente 1006-2014; sentencia de } 8 \text { de } \\
\text { noviembre de 2016, expediente } 3438-2016 \text {; } \\
\text { sentencia de } 20 \text { de julio de 2017, expediente } \\
\text { 1264-2017; sentencia de } 24 \text { de enero de } 2019 \text {, } \\
\text { expediente 1705-2017; sentencia de } 29 \text { de } \\
\text { enero de 2019, expediente 3239-2017. }\end{array}$ \\
\hline $\begin{array}{l}\text { Protocolo Adicional a la } \\
\text { Convención Americana sobre } \\
\text { Derechos Humanos en materia } \\
\text { de Derechos Económicos, } \\
\text { Sociales y Culturales }\end{array}$ & $\begin{array}{l}\text { Sentencia de } 8 \text { de septiembre de 2015, } \\
\text { expedientes acumulados 2-2015, 151-2015, } \\
298-2015 \text { y 1045-2015; sentencia de 21 de } \\
\text { octubre de 2015, expediente 5290-2014; } \\
\text { sentencia de } 20 \text { de julio de 2017, expediente } \\
\text { 1264-2017. }\end{array}$ \\
\hline $\begin{array}{l}\text { Pacto Internacional de Derechos } \\
\text { Civiles y Políticos }\end{array}$ & $\begin{array}{l}\text { Sentencia de } 13 \text { de agosto de } 2015 \text {, expediente } \\
\text { 1732-2014; sentencia de } 26 \text { de noviembre de } \\
\text { 2015, expediente 1006-2014; sentencia de } 5 \\
\text { de julio de 2016, expedientes acumulados } \\
\text { 4783-2013, 4812-2013 y 4813-2013. }\end{array}$ \\
\hline $\begin{array}{l}\text { Pacto Internacional de Derechos } \\
\text { Económicos, Sociales y } \\
\text { Culturales }\end{array}$ & $\begin{array}{l}\text { Sentencia de } 8 \text { de septiembre de } 2015 \text {, } \\
\text { expedientes acumulados 2-2015, 151-2015, } \\
298-2015 \text { y 1045-2015; sentencia de } 10 \\
\text { de marzo de 2016, expediente 1467-2014; } \\
\text { sentencia de } 5 \text { de julio de 2016, expedientes } \\
\text { acumulados 4783-2013, 4812-2013 y 4813- } \\
\text { 2013; sentencia de 21 de junio de 2017, } \\
\text { expediente 943-2017. }\end{array}$ \\
\hline $\begin{array}{l}\text { Convención contra la Tortura } \\
\text { y otros Tratos o Penas Crueles, } \\
\text { Inhumanos o Degradantes }\end{array}$ & $\begin{array}{l}\text { Sentencia de } 17 \text { de julio de } 2012 \text {, expediente } \\
1822-2011 \text {; sentencia de } 7 \text { de agosto de } \\
2013 \text {, expediente } 1497-2013 \text {; sentencia de } \\
19 \text { de marzo de } 2014 \text {, expediente } 1552- \\
2013 \text {; sentencia de } 7 \text { de diciembre de } 2017 \text {, } \\
\text { expediente } 2841-2017 \text {. }\end{array}$ \\
\hline
\end{tabular}




\begin{tabular}{|c|c|}
\hline Instrumento internacional & $\begin{array}{c}\text { Sentencias emitidas por la Corte de } \\
\text { Constitucionalidad }\end{array}$ \\
\hline $\begin{array}{l}\text { Protocolo Facultativo de la } \\
\text { Convención contra la Tortura } \\
\text { y otros Tratos o Penas Crueles, } \\
\text { Inhumanos o Degradantes }\end{array}$ & $\begin{array}{l}\text { Sentencia de } 7 \text { de agosto de } 2013 \text {, expediente } \\
\text { 1497-2013; sentencia de } 19 \text { de marzo de } 2014 \text {, } \\
\text { expediente 1552-2013; sentencia de } 7 \text { de } \\
\text { diciembre de 2017, expediente 2841-2017. }\end{array}$ \\
\hline $\begin{array}{l}\text { Convención Interamericana para } \\
\text { Prevenir y Sancionar la Tortura }\end{array}$ & $\begin{array}{l}\text { Sentencia de } 17 \text { de julio de } 2012 \text {, expediente } \\
\text { 1822-2011. }\end{array}$ \\
\hline $\begin{array}{l}\text { Convención sobre los } \\
\text { Derechos del Niño y estándares } \\
\text { internacionales protectores de } \\
\text { los derechos de niños, niñas y } \\
\text { adolescentes }\end{array}$ & $\begin{array}{l}\text { Sentencia de } 26 \text { de noviembre de } 2015 \text {, } \\
\text { expediente } 1006-2014 \text {; sentencia de } 5 \text { de } \\
\text { julio de 2016, expedientes acumulados } 4783- \\
2013,4812-2013 \text { y } 4813-2013 \text {; sentencia de } 12 \\
\text { de octubre de 2017, expediente 2709-2017; } \\
\text { sentencia de } 24 \text { de octubre de } 2017 \text {, expediente } \\
\text { 6276-2016; sentencia de } 22 \text { de mayo de } 2018 \text {, } \\
\text { expediente 5024-2017; sentencia de } 8 \text { de } \\
\text { agosto de } 2018 \text {, expediente } 858-2016 \text {. }\end{array}$ \\
\hline $\begin{array}{l}\text { Convención sobre la Eliminación } \\
\text { de todas las Formas de } \\
\text { Discriminación contra la Mujer }\end{array}$ & $\begin{array}{l}\text { Sentencia de } 26 \text { de noviembre de } 2015 \text {, } \\
\text { expediente 1006-2014; sentencia de } 29 \text { de } \\
\text { enero de } 2019 \text {, expediente } 3239-2017 \text {. }\end{array}$ \\
\hline $\begin{array}{l}\text { Convención Interamericana para } \\
\text { Prevenir, Sancionar y Erradicar } \\
\text { la Violencia contra la Mujer } \\
\text { "Convención de Belém do Pará" }\end{array}$ & $\begin{array}{l}\text { Sentencia de } 30 \text { de octubre de } 2012 \text {, expediente } \\
\text { 1240-2012; sentencia de } 6 \text { de febrero de } 2017 \text {, } \\
\text { expediente } 4136-2016 \text {. }\end{array}$ \\
\hline $\begin{array}{llr}\text { Convención } & \text { sobre la } \\
\text { Nacionalidad de la Mujer Casada }\end{array}$ & $\begin{array}{l}\text { Sentencia de } 29 \text { de enero de } 2019 \text {, expediente } \\
3239-2017\end{array}$ \\
\hline $\begin{array}{l}\text { Tratados internacionales en } \\
\text { materia de derechos de la mujer, } \\
\text { de forma general }\end{array}$ & $\begin{array}{l}\text { Sentencia de } 7 \text { de febrero de } 2018 \text {, expediente } \\
4221-2017 .\end{array}$ \\
\hline $\begin{array}{l}\text { Reglas Mínimas de las Naciones } \\
\text { Unidas sobre las medidas no } \\
\text { privativas de la libertad (Reglas } \\
\text { de Tokio) }\end{array}$ & $\begin{array}{l}\text { Sentencia de } 25 \text { de octubre de } 2018 \text {, expediente } \\
5614-2016 .\end{array}$ \\
\hline $\begin{array}{l}\text { Convención sobre los Derechos } \\
\text { de las Personas con Discapacidad }\end{array}$ & $\begin{array}{l}\text { Sentencia de } 6 \text { de febrero de } 2017 \text {, expediente } \\
4136-2016 .\end{array}$ \\
\hline
\end{tabular}




\begin{tabular}{|c|c|}
\hline Instrumento internacional & $\begin{array}{c}\text { Sentencias emitidas por la Corte de } \\
\text { Constitucionalidad }\end{array}$ \\
\hline Derecho de consulta & $\begin{array}{l}\text { Sentencia de } 21 \text { de diciembre de } 2009 \text {, } \\
\text { expediente } 3878-2007 \text {; sentencia de } 25 \text { de } \\
\text { marzo de 2015, expedientes acumulados } \\
\text { 156-2013 y 159-2013; sentencia de } 10 \text { de } \\
\text { septiembre de 2015, expediente 1149-2012; } \\
\text { sentencia de } 12 \text { de enero de 2016, expediente } \\
\text { 3753-2014; sentencia de } 12 \text { de enero de 2016, } \\
\text { expediente 411-2014; sentencia de } 7 \text { de julio } \\
\text { de 2016, expediente 5711-2013; sentencia } 29 \\
\text { de junio 2017, expediente } 3120 \text {-2016. }\end{array}$ \\
\hline $\begin{array}{l}\text { C } 169 \text { y estándares internacionales } \\
\text { protectores de los derechos } \\
\text { humanos de pueblos indígenas y } \\
\text { sus miembros }\end{array}$ & $\begin{array}{l}\text { Sentencia de } 30 \text { de mayo de } 2012 \text {, expedientes } \\
\text { acumulados } 401-2012 \text { y } 489-2012 \text {; sentencia } \\
\text { de } 10 \text { de marzo de } 2016 \text {, expediente } 1467- \\
2014 \text {; sentencia de } 5 \text { de julio de 2016, } \\
\text { expedientes acumulados } 4783-2013 \text {, 4812- } \\
2013 \text { y } 4813-2013 \text {; sentencia de } 26 \text { de mayo } \\
\text { de } 2017 \text {, expedientes acumulados } 90-2017 \text {, } \\
\text { 91-2017 y } 92-2017 \text {; sentencia de } 21 \text { de junio } \\
\text { de } 2017 \text {, expediente } 943-2017 \text {. }\end{array}$ \\
\hline $\begin{array}{l}\text { Declaración de Naciones Unidas } \\
\text { sobre los Derechos de los Pueblos } \\
\text { Indígenas }\end{array}$ & $\begin{array}{l}\text { Sentencia de } 5 \text { de julio de 2016, expedientes } \\
\text { acumulados 4783-2013, 4812-2013 y 4813- } \\
2013 \text {. }\end{array}$ \\
\hline Jurisprudencia de la Corte IDH & $\begin{array}{l}\text { Sentencia de } 24 \text { de octubre de } 2017 \text {, expediente } \\
\text { 6276-2016; sentencia de } 22 \text { de mayo de } 2018 \text {, } \\
\text { expediente 5024-2017; sentencia de } 26 \text { de } \\
\text { junio de 2018, expediente } 3448-2017 \text {. }\end{array}$ \\
\hline $\begin{array}{l}\text { Convenio } 98 \text { de la Organización } \\
\text { Internacional de Trabajo sobre } \\
\text { el derecho de sindicación y de } \\
\text { negociación colectiva }\end{array}$ & $\begin{array}{l}\text { Sentencia de } 14 \text { de febrero de } 2017 \text {, expediente } \\
\text { 1490-2016. }\end{array}$ \\
\hline $\begin{array}{l}\text { Convenio } 154 \text { de la Organización } \\
\text { Internacional de Trabajo sobre la } \\
\text { negociación colectiva }\end{array}$ & $\begin{array}{l}\text { Sentencia de } 14 \text { de febrero de 2017, expediente } \\
\text { 1490-2016. }\end{array}$ \\
\hline $\begin{array}{l}\text { Convención Internacional sobre } \\
\text { la Protección de los Derechos } \\
\text { de Todos los Trabajadores } \\
\text { Migratorios y sus Familiares }\end{array}$ & $\begin{array}{l}\text { Sentencia de } 29 \text { de enero de 2019, expediente } \\
\text { 3239-2017. }\end{array}$ \\
\hline $\begin{array}{l}\text { Convención sobre el Estatuto de } \\
\text { los Apátridas }\end{array}$ & $\begin{array}{l}\text { Sentencia de } 29 \text { de enero de 2019, expediente } \\
3239-2017 \text {. }\end{array}$ \\
\hline
\end{tabular}




\section{REFLEXIONES FINALES}

Conforme las delimitaciones conceptuales plasmadas en la sentencia dictada dentro del expediente 1822-2011, el bloque de constitucionalidad no alude, en el ámbito guatemalteco, a un conjunto de normas previamente identificadas. El mecanismo dispuesto por la CC para ir delimitando los instrumentos que lo integran, implica que, a partir del conocimiento de cada caso en concreto, el Tribunal iría determinado cuál material sería considerado como parte integrante. En esa tarea de escogencia, la Corte ha ido incluyendo, a lo largo de su desarrollo jurisprudencial, importantes instrumentos internacionales de protección de derechos. Ahora bien, partiendo del contenido del artículo 46 constitucional, la Corte pudo haber optado por señalar que conformaban la noción, de forma general, los tratados ratificados por Guatemala en materia de derechos humanos. Esta vía no ha sido la elegida.

De lo señalado, merece ser indicado que, por una parte, exista la posibilidad de que tratados de carácter internacional que reconozcan derechos no sean dotados de valor constitucional de forma contundente, como podría suceder, por ejemplo, con el C 169 de la OIT, respecto del cual existe una jurisprudencia ondulante.

A pesar de lo anterior, también debe considerarse que el sentido abierto que ha preferido la CC brinda una oportunidad que se valora como positiva, y es la de incluir, dentro del bloque, instrumentos internacionales distintos a los tratados, que podrían entenderse como no comprendidos en los alcances del artículo 46 constitucional. ${ }^{10}$

10 Sobre el tema, se explica que si bien, el artículo 46 precitado refiere la preeminencia de los tratados y convenciones sobre el derecho interno, para efectos del derecho internacional, las convenciones se enmarcan dentro de la figura del tratado, conforme el artículo 2, literal a) de la Convención de Viena sobre el Derecho de los Tratados -instrumento que ya había sido firmado y entrado en vigor internacionalmente al aprobarse la actual Constitución-. Tratado incluiría, indistintamente, términos como convención, convenio, protocolo, pacto, carta, constitución, estatuto, acuerdo u otras denominaciones exclusivas de tratados internacionales bilaterales. Además, se señala que los tratados se diferencian de las declaraciones de voluntad, de las cuales ha sido dicho que si bien pueden ser alcanzadas por los sujetos de derecho internacional, únicamente constituyen manifestaciones de voluntad política. Un ejemplo sería la Declaración Universal de Derechos Humanos (Ríos, 2013). 
En este último campo se inscriben las declaraciones o la jurisprudencia de tribunales internacionales. En ese sentido, la Corte ha proferido fallos de los que puede extraerse que la Declaración Universal de Derechos Humanos, la Declaración de Naciones Unidas sobre los Derechos de los Pueblos Indígenas ${ }^{11}$ y las Reglas de Tokio forman parte del bloque. Además, en al menos tres pronunciamientos, ha incluido dentro de la figura del bloque a la jurisprudencia de la Corte IDH, tema que, por la importancia de sus implicaciones, será abordado con mayor detenimiento más adelante.

Otro aspecto que se estima de importante mención es el evento de que normativa interna distinta al texto formal de la constitución pueda ser parte del bloque. Valdría discutir, por ejemplo, la conveniencia de que los Acuerdos de Paz (el último suscrito en 1996) obtuvieran el reconocimiento de instrumentos de valía constitucional, atendiendo a la importancia de los compromisos adquiridos como ruta para la reconciliación nacional y los bajos índices de cumplimiento reportados; ${ }^{12}$ esa situación encontraría, de ostentar tales acuerdos un estatus especial, un mecanismo de exigibilidad reforzado a través de la justicia constitucional.

El bloque de constitucionalidad ciertamente potencializa la efectividad de los instrumentos internacionales que lo conforman. La observancia de estos ya no sería exigible únicamente a través de la invocación del contenido de los artículos 26, 27 y 31.1 de la Convención de Viena sobre el Derecho de los Tratados (1969) -referentes a los principios de pacta sunt servanda y buena fe, así como la improcedencia de invocar disposiciones de derecho interno como

11 Sobre la Declaración de las Naciones Unidas sobre los Derechos de los Pueblos Indígenas es afirmado, de manera general, que, aun no teniendo carácter formalmente vinculante, contiene derechos como la libre determinación y la no discriminación que se enuncian en el derecho convencional internacional de derechos humanos de carácter vinculante e incluso consuetudinario. Esto obedece a un consenso mundial sobre los derechos en mención. (Naciones Unidas, 2013).

12 Aunque fue emitida la Ley Marco de los Acuerdos de Paz, decreto 52-2005 del Congreso de la República, con el objeto de plasmar en una ley específica las normas y mecanismos que garantizaran la continuidad del proceso, dándose así reconocimiento jurídico a los Acuerdos como compromisos estatales, transcurridos 20 años desde la firma de los Acuerdos de Paz, se reportó que 50,4\% de los acuerdos siguen sin aplicarse, particularmente los relacionados con la desigualdad y la no discriminación (Oficina del Alto Comisionado de las Naciones Unidas para los Derechos Humanos, 2019). 
justificación del incumplimiento de un tratado- y el artículo 149 constitucional -referente a la forma en que el Estado de Guatemala normará sus relaciones con otros Estados ${ }^{13}$ sino además, por medio de la construcción jurisprudencial que, con base en los artículos 44 y 46 constitucionales, ha efectuado el Tribunal Constitucional y que les asigna rango constitucional.

Los instrumentos internacionales son dotados, por lo tanto, de la fuerza normativa que caracteriza a las disposiciones constitucionales, con lo cual, no pueden ser ya considerados como meras declaraciones cuya eficacia se supedite al criterio discrecional de los órganos estatales. Lo indicado se traduce en que lo normado en materia de derechos humanos en el ámbito internacional, junto con lo dispuesto expresamente en el texto supremo, condiciona la producción de leyes y, desea resaltarse, también de los actos que provienen de los órganos públicos; además, que situaciones jurídicas que se aparten de lo dispuesto en esas normatividades puedan ser sujetas a control de constitucionalidad, en resguardo del principio de supremacía constitucional.

Conviene destacar que la misma CC ha sido clara en señalar que la interpretación de las normas jurídicas debe realizarse, tanto por los órganos del Estado (preponderantemente, se agrega, a través del papel que fungen los jueces), como por los particulares, de forma coherente con los instrumentos que se incluyen en el bloque de constitucionalidad. Esta consideración envuelve que la misma Constitución, como también lo ha expresado el alto tribunal constitucional, sea interpretada en análisis y ponderación de los materiales jurídicos contenidos en el bloque.

Asociando lo indicado con la distinción que realiza Sagüés (2015) en el plano del control de convencionalidad, respecto de los papeles represivo y constructivo o positivo que derivan de su práctica, ${ }^{14}$ la Corte, con tales

13 “Artículo 149. De las relaciones internacionales. Guatemala normará sus relaciones con otros Estados, de conformidad con los principios, reglas y prácticas internacionales con el propósito de contribuir al mantenimiento de la paz y la libertad, al respeto y defensa de los derechos humanos, al fortalecimiento de los procesos democráticos e instituciones internacionales que garanticen el beneficio mutuo y equitativo entre los Estados.”.

14 El primero, concebido desde el Caso Almonacid Arellano vs. Chile (2006), consiste en la inaplicación de reglas del derecho interno opuestas a la CADH (y en general, de los tratados internacionales sobre derechos humanos ratificados por un Estado, según aclara 
consideraciones, remarca que el efecto del bloque de constitucionalidad no se agota en que esta figura se constituya como parámetro para la expulsión o inaplicación de preceptos a cargo de los órganos jurisdiccionales dotados con competencia para ello (que, emulando lo señalado por Sagüés, constituiría el papel represivo), sino involucra a la totalidad de autoridades estatales y particulares, quienes poseen un rol positivo, consistente en el deber, al aplicar el derecho nacional, de realizar una interpretación conforme a la normatividad constituida como bloque.

Otra implicancia de la introducción del bloque de constitucionalidad debe observarse a la luz de su estrecha relación con el deber de aplicación del control de convencionalidad. Mucho se ha discutido sobre el grado de exigencia del deber de los Estados en la aplicación del referido control y la operatividad que la figura pueda tener en el interior de cada país. Ambas cuestiones se encuentran relacionadas con las distintas modalidades de incorporación del derecho internacional en los ordenamientos jurídicos de los Estados parte de la CADH. Se condicionan, consecuentemente, por las normas referentes a la jerarquía normativa de la Convención, tratados del Sistema Interamericano e interpretaciones de la Corte IDH, o bien, su incorporación al bloque de constitucionalidad. En su facultad legítima de decidir el nivel de incorporación de las fuentes del derecho internacional como derecho nacional, los Estados pueden disponer, por ejemplo, si tales interpretaciones poseen rango constitucional -como es el caso de Costa Rica- o bien, constituyen un criterio hermenéutico relevante, no necesariamente decisivo -como en el caso de Colombia- (González Domínguez, 2017).

En Guatemala, la CADH y otros instrumentos que pertenecen al corpus iuris interamericano, así como las interpretaciones realizadas por la Corte IDH, forman parte del bloque de constitucionalidad, según fue denotado en párrafos precedentes. Esto conlleva que las autoridades estatales deban

el mismo autor) y la doctrina sentada por la Corte IDH; el segundo, perceptible con claridad a partir del Caso Radilla Pacheco vs. México, hace alusión a la necesidad de que las interpretaciones constitucionales y legislativas locales se adecuen a los principios establecidos por la jurisprudencia del tribunal regional lo que, en definitiva, implica realizar la "interpretación conforme" del derecho local con la CADH y la jurisprudencia de la Corte IDH. 
concebir la aplicación del control de convencionalidad en un grado reforzado de vinculatoriedad, ya no solo a partir de los fundamentos que típicamente sustentan su aplicación (artículos 1.1, 2 y 29 de la CADH, así como de los ya citados artículos de la Convención de Viena sobre el Derecho de los Tratados), sino además, en atención a los instrumentos que componen el bloque de constitucionalidad. El valor decisivo de la jurisprudencia que emana de la Corte regional en la aplicación del derecho, como consecuencia de su visualización como parámetro de constitucionalidad, resulta relevante, pues otorga la posibilidad de aumentar el nivel de protección en favor de las personas; además, las autoridades estatales guatemaltecas poseen una mejor posición para defender el empleo del producto hermenéutico del tribunal interamericano a través de ese cause.

Las consecuencias jurídicas que acarrea la incorporación del bloque de constitucionalidad a las que se ha hecho mención en apartados precedentes, denotan la necesidad de procurar, por un lado, una línea jurisprudencial conteste sobre el criterio definido para considerar a un instrumento como parte del bloque de constitucionalidad, y por el otro, claridad cuando se aluda a los elementos integrantes de esta noción. Vale notar la importancia de que, por ejemplo, cuando se haga referencia a la inclusión, en el bloque, de estándares internacionales o tratados internacionales en general, como ha acontecido en temas de derechos de niños, niñas y adolescentes, mujeres y pueblos indígenas, se delineen con mayor precisión los instrumentos que pueden ser considerados como aludidos.

Además, es necesaria la consolidación de criterios doctrinarios, teniéndose un área de oportunidad, por ejemplo, en lo concerniente a los instrumentos internacionales de protección de colectividades e individuos indígenas. Esto, no porque se considere que, a raíz de la falta de una inclusión contundente, proceda alegar que las obligaciones a las que se suscribió el Estado de Guatemala en esos documentos jurídicos no le son exigibles. Más bien, su propósito radicaría en que la Corte asuma posturas que contribuyan a reafirmar la necesidad de garantizar el goce de los derechos de tales sujetos en aquellos ámbitos en los que el despliegue de la normatividad interna no ha sido suficiente, impregnando de contenido constitucional los instrumentos que brinden una mejor protección y, 
por tanto, construyendo vías que refuercen la exigibilidad de los compromisos existentes.

Es importante referir en este punto que la inexistencia de una decisión en la que el tribunal constitucional haya incorporado explícita o tácitamente determinado tratado internacional al bloque no debe verse en lo absoluto como una disminución del nivel de vinculatoriedad que ese tratado posee, ni concebirse como argumento que justifique la inobservancia de las obligaciones correlativas a los derechos que la normativa internacional reconozca. En otras palabras, el reconocimiento de la valía constitucional de ciertos instrumentos no debe apreciarse como una limitación a la exigencia de los deberes de respeto, protección y garantía de los derechos contenidos en tratados internacionales que aún no han sido insertos al bloque, puesto que esos derechos ya poseen reconocimiento constitucional a partir del artículo 44 del texto supremo.

Así, el principal beneficio que se aprecia del mecanismo definido por la $\mathrm{CC}$ es el de brindar la oportunidad para que materiales jurídicos pertenecientes a categorías distintas a la que prevé el artículo 49 de la norma suprema puedan ser dotados de mayor fuerza jurídica. Por lo tanto, es conveniente concebir el bloque, de la manera en que lo ha configurado el tribunal constitucional, no como una figura limitante de la observancia de los derechos humanos, sino un cauce que, junto con otras posibilidades interpretativas, como el principio pro persona, permita superar argumentaciones tendientes a dar una preferencia inmóvil a una u otra fuente, según su pertenencia al ordenamiento nacional o internacional, o bien, que resten vinculatoriedad a importantes instrumentos internacionales, posturas que, en algún evento, pudieran conllevar incumplimiento de compromisos internacionales o redundar en una protección menos favorable para el tutelado.

Apuntadas las significativas implicancias de la figura en comento, conviene señalar que, dado el número considerable de casos en los que la noción del bloque de constitucionalidad es invocada, representaría una herramienta invaluable la sistematización que, de parte del mismo seno del tribunal constitucional, pudiera realizarse, respecto a los pronunciamientos emitidos, 
con el objeto de que la figura pueda ser mejor comprendida y se difunda de maneras más precisas en los distintos campos de aplicación jurídica.

Finalmente, no se desea pasar por alto que, de la mano del adecuado desarrollo del bloque, la caracterización multinivel de la protección de derechos humanos requiere, como ya fue adelantado, de la observancia del principio pro persona -con una visión no circunscrita al continente de los instrumentos que conforman el bloque-, como otro mecanismo armonizador de los distintos niveles de normatividades y autoridades existentes. Ambos elementos favorecen a la concepción del derecho internacional de los derechos humanos y lo decidido por los órganos supranacionales, como insumo para el perfeccionamiento del derecho interno y de las interpretaciones efectuadas por los órganos locales. 


\section{BIBLIOGRAFÍA}

Amaya-Villareal, Á. F., \& Guzmán-Duarte, V. (2017). La naturaleza juridico-internacional de los acuerdos de paz y sus consecuencias en la implementación. International Law, Revista Colombiana de Derecho Internacional , 41-60.

Asamblea Nacional Constituyente. (1985). Constitución Política de la República de Guatemala. Guatemala: Corte de Constitucionalidad.

Casal, J. M. (2010). Aproximación a las funciones de la jurisdicción constitucional. En A. von Bogdandy, E. Ferrer Mac-Gregor, \& M. Morales Antonazzi, La justicia constitucional y su internacionalización ¿Haciua un Ius Constitutionale Commune en América Latina? (págs. 63-86). México: Universidad Nacional Autónoma de México.

Congreso Nacional Constituyente. (22 de agosto de 1994). Constitución de la Nación Argentina. Santa Fe.

Constitución. (4 de octubre de 1958). Francia.

Convención de Viena sobre el Derecho de los Tratados U.N. Doc A/CONF.39/27 (1969). (23 de mayo de 1969). Viena.

Corte de Constitucionalidad. (31 de julio de 1990). Dictamen dentro del expediente 90-90. Dictamen. Guatemala.

(23 de noviembre de 2017). Dictamen dentro del expediente 919-2016. Dictamen . Guatemala.

(30 de mayo de 2012). Sentencia dentro de los expedientes acumulados 401-2012 y 489-2012. Apelación de sentencia en amparo . Guatemala.

(16 de agosto de 2016). Sentencia dentro de los expedientes acumulados 5341-2015 y 5350-2015. Apelación de sentencia de amparo . Guatemala.

(16 de junio de 2015). Sentencia dentro de los expedientes acumulados 5909-2013, 5985-2013, 48-2014 y 439-2014. Amparo en única instancia . Guatemala.

(26 de mayo de 2017). Sentencia dentro de los expedientes acumulados 90-2017, 91-2017 y 92-2017. Apelación de sentencia en amparo . Guatemala.

(5 de julio de 2016). Sentencia dentro de los expedientes acumulados acumulados 4783-2013, 4812-2013 y 4813-2013. Apelación de sentencia en amparo . Guatemala.

(26 de noviembre de 2015). Sentencia dentro del expediente 1006-2014. Inconstitucionalidad general parcial . Guatemala.

(28 de febrero de 2013). Sentencia dentro del expediente 1008-2012. Inconstitucionalidad general total. Guatemala. 
(8 de septiembre de 1998). Sentencia dentro del expediente 1042-97. Apelación de sentencia en amparo . Guatemala.

(12 de marzo de 1997). Sentencia dentro del expediente 131-95. Inconstitucionalidad general parcial . Guatemala.

(6 de agosto de 2013). Sentencia dentro del expediente 143-2013. Inconstitucionalidad general parcial y total. Guatemala.

(10 de marzo de 2016). Sentencia dentro del expediente 1467-2014. Apelación de sentencia en amparo. Guatemala.

(20 de mayo de 1998). Sentencia dentro del expediente 159-97. Inconstitucionalidad general parcial. Guatemala.

(17 dejulio de 2012). Sentencia dentro del expediente 1822-2011. Inconstitucionalidad general parcial por omisión. Guatemala.

(17 de julio de 2018). Sentencia dentro del expediente 1907-2017. Amparo en única instancia. Guatemala.

(28 de junio de 2016). Sentencia dentro del expediente 2404-2014. Amparo en única instancia. Guatemala.

(19 de octubre de 1990). Sentencia dentro del expediente 280-90. Guatemala.

(23 de diciembre de 2015). Sentencia dentro del expediente 3137-2015. Apelación de sentencia en amparo. Guatemala.

(18 de diciembre de 2014). Sentencia dentro del expediente 3340-2013. Apelación de sentencia en amparo. Guatemala.

(26 de marzo de 1996). Sentencia dentro del expediente 334-95. Inconstitucionalidad general parcial . Guatemala.

(14 de marzo de 2016). Sentencia dentro del expediente 3370-2015. Apelación de sentencia en amparo. Guatemala.

(21 de diciembre de 2009). Sentencia dentro del expediente 3878-2007. Apelación de sentencia en amparo. Guatemala.

(17 de noviembre de 2016). Sentencia dentro del expediente 4076-2016. Inconstitucionalidad de ley en caso concreto . Guatemala.

(24 de abril de 2013). Sentencia dentro del expediente 4708-2012. Amparo en única instancia. Guatemala.

(4 de febrero de 2015). Sentencia dentro del expediente 5237-2013. Inconstitucionalidad general total . Guatemala. 
(21 de junio de 2017). Sentencia dentro del expediente 943-2017. Apelación de sentencia en amparo. Guatemala.

Favoreau, L. (1990). El bloque de la constitucionalidad. Revista del Centro de Estudios Constitucionales , 45-68.

Góngora Mera, M.E.(2014).La difusión del bloque de constitucionalidad en la jurisprudencia latinoamericana y su potencial en la construcción del ius constitutionale commune latinoamericano. En A. von Bogdandy, H. Fix-Fierro, \& M. Morales Antoniazzi, Ius Constitutionale Commune en América Latina: Rasgos, Potencialidades y Desafíos (págs. 301-327). México: Universidad Nacional Autónoma de México.

González Domínguez, P. (2017). La doctrina del control de convencionalidad a la luz del principio de subsidiariedad. Estudios Constitucionales , 55-98.

Naciones Unidas, D. H. (2013). Los pueblos indígenas y el sistema de derechos humanos de las Naciones Unidas . Nueva York y Ginebra: Naciones Unidas.

Oficina del Alto Comisionado de las Naciones Unidas para los Derechos Humanos. (2019). Informe de la Oficina del Alto Comisionado de las Naciones Unidas para los Derechos Humanos sobre las actividades de la Oficina del Alto Comisionado en Guatemala A/ HRC/40/3/Add.1. New York: Asamblea General de las Naciones Unidas.

Ríos, E. M. (2013). Derecho guatemalteco de los tratados internacionales. Guatemala: Universidad Rafael Landívar, Instituto de Investigaciones Jurídicas.

Sagüés, N. P. (2015). Notas sobre el control ejecutivo de convencionalidad. En C. Steiner, Anuario de Derecho Constitucional Latinoamericano 2015 (págs. 141-149). Bogotá: Unión Gráfica. 